\title{
CNPase Expression in Olfactory Ensheathing Cells
}

\author{
Christine Radtke, ${ }^{1,2,3}$ Masanori Sasaki, ${ }^{1,2}$ Karen L. Lankford, ${ }^{1,2}$ \\ Vittorio Gallo, ${ }^{4}$ and Jeffery D. Kocsis ${ }^{1,2}$ \\ ${ }^{1}$ Department of Neurology and Center for Neuroscience and Regeneration Research, Yale University School of Medicine, \\ New Haven, CT 06510, USA \\ ${ }^{2}$ Rehabilitation Research Center, Veterans Affairs Connecticut Healthcare System, West Haven, CT 06516, USA \\ ${ }^{3}$ Department of Plastic, Hand and Reconstructive Surgery, Hannover Medical School, 30659 Hannover, Germany \\ ${ }^{4}$ Center for Neuroscience Research, Children's Research Institute, Children's National Medical Center, Washington, DC 20010, USA
}

Correspondence should be addressed to Jeffery D. Kocsis, jeffery.kocsis@yale.edu

Received 16 July 2011; Accepted 17 August 2011

Academic Editor: Ken-ichi Isobe

Copyright (C) 2011 Christine Radtke et al. This is an open access article distributed under the Creative Commons Attribution License, which permits unrestricted use, distribution, and reproduction in any medium, provided the original work is properly cited.

\begin{abstract}
A large body of work supports the proposal that transplantation of olfactory ensheathing cells (OECs) into nerve or spinal cord injuries can promote axonal regeneration and remyelination. Yet, some investigators have questioned whether the transplanted OECs associate with axons and form peripheral myelin, or if they recruit endogenous Schwann cells that form myelin. Olfactory bulbs from transgenic mice expressing the enhanced green fluorescent protein (eGFP) under the control of the 2-3-cyclic nucleotide 3-phosphodiesterase (CNPase) promoter were studied. CNPase is expressed in myelin-forming cells throughout their lineage. We examined CNPase expression in both in situ in the olfactory bulb and in vitro to determine if OECs express CNPase commensurate with their myelination potential. eGFP was observed in the outer nerve layer of the olfactory bulb. Dissociated OECs maintained in culture had both intense eGFP expression and CNPase immunostaining. Transplantation of OECs into transected peripheral nerve longitudinally associated with the regenerated axons. These data indicate that OECs in the outer nerve layer of the olfactory bulb of CNPase transgenic mice express CNPase. Thus, while OECs do not normally form myelin on olfactory nerve axons, their expression of CNPase is commensurate with their potential to form myelin when transplanted into injured peripheral nerve.
\end{abstract}

\section{Introduction}

The only example of successful regeneration from peripheral neurons into the central nervous system (CNS) is within the olfactory system, where axons regenerate throughout life from the nasal mucosa into the olfactory bulbs of the brain. A specialized glia cell, the olfactory ensheathing cell (OEC), spans the CNS-peripheral nervous system (PNS) junction and is thought to bridge the gap to allow peripheral axons to penetrate the brain. Indeed, transplantation of cultured OECs leads to enhanced regeneration and remyelination of injured peripheral nerve $[1,2]$.

A large body of work supports the proposal that transplantation of OECs into various spinal cord injury and demyelination models can promote axonal regeneration, remyelination, and functional recovery [2-12]. Yet, some investigators have questioned whether the transplanted OECs form peripheral myelin, or if they recruit endogenous SCs that form myelin $[13,14]$. These events are not mutually exclusive in that transplanted OECs could both facilitate SC invasion into the spinal cord and as well as myelinate axons. It is important to note that Franklin et al. [11] demonstrated myelination in the spinal cord by an OEC cell line, strongly suggesting that OECs can indeed remyelinate axons [9].

Although OECs do not form myelin on fine caliber olfactory nerve fibers during normal development, numerous studies have shown that OECs can remyelinate both CNS $[15-18]$ and PNS $[1,2]$ axons in a variety of lesion models. This discrepancy between the normal developmental fate OECs in vivo and their differentiation when transplanted into demyelinated regions has raised the question of whether the myelination observed in OEC transplanted lesions is due 
to contamination of OEC preparations with Schwann cells, oligodendrocyte precursor cells (OPCs), or even neural stem cells $[13,19,20]$.

The enzyme $2^{\prime}, 3^{\prime}$-cyclic nucleotide $3^{\prime}$-phosphodiesterase or CNPase is expressed in both oligodendrocytes and SCs and is considered a marker for myelin-forming cells, although it is also found in other cells, including lymphocytes and photoreceptors as well as some neurons in long-term culture [21]. CNPase is both membrane bound and linked to microtubules and is the third most abundant myelin protein in the CNS, representing $4 \%$ of CNS myelin proteins. The role of this enzyme is not yet clear, although over expression mutations suggest that CNPase plays a role in myelin compaction $[22,23]$. CNPase is the earliest myelination-specific protein expressed by oligodendrocytes and is expressed in both myelinating and nonmyelinating oligodendrocytes and SCs. CNPase is therefore considered to be marker for the potential of cells to produce myelin, rather than an indication of actual myelination and evidence of CNPase expression by OECs would therefore provide strong support for the idea that OECs are capable of forming myelin.

Studies using immunostaining with antiCNPase antibodies yielded ambiguous and conflicting results for CNPase expression by OECs from the olfactory bulb and olfactory neuroepithelium. CNPase staining was observed on some, but not all presumptive OECs in explant cultures from the olfactory bulb [24], but not on presumptive OECs in dissociated cultures from the nasal epithelium cultured on astrocyte feeder layers [25]. Immunostaining of developing olfactory bulb focused on CNPase staining of oligodendrocytes and did not report CNPase staining of OECs [26]. It is not clear therefore whether CNPase is expressed by OECs only in specific environments, or whether levels of CNPase may be too low to reliably detect with standard antibody staining protocols.

The recent development of a transgenic mouse in which an enhanced green fluorescent protein (eGFP) is linked to expression of CNPase [21] has provided an opportunity to evaluate CNPase expression by OECs in a variety of environments. Since the use of a reporter gene eliminates problems with both false positive and false negative antibody staining, GFP transgenic mice would allow detection of CNPase expression without the need to optimize staining protocols to specific tissue or culture conditions. In this study we have examined CNPase-linked eGFP expression by OECs in the olfactory bulb and in dissociated cell culture. The results indicate that OECs express CNPase in the outer nerve layer of the olfactory bulb as well as in culture, thus indicating that OECs express an important enzyme required for myelination. This provides further evidence of the intrinsic capability of OECs to myelinate axons upon transplantation.

\section{Methods}

2.1. Isolation and Characterization of OECs from CNPEGFP Mouse. The CNP-EGFP mouse has been described previously $[15,27]$. Freshly isolated OECs were obtained as reported previously $[16,28,29]$. Olfactory bulbs were removed from 4- to 8-week-old transgenic mice expressing GFP-CNPase and dissected free of meninges. The caudal one-third of the bulb was removed and discarded along with as much white matter as possible to isolate the outer nerve layer. Tissue was minced finely with a pair of scalpel blades (\#10) on plastic culture dishes, and nonadherent tissue was washed from culture dishes and incubated for $25 \mathrm{~min}$ in collagenase A $(0.75 \mathrm{mg} / \mathrm{mL}$; Roche, Indianapolis, I, USA), collagenase $\mathrm{D}(0.75 \mathrm{mg} / \mathrm{mL}$; Roche $)$, and papain (12 U/mL; Worthington, Lakewood, NJ, USA) in calciumfree complete saline solution with trace cysteine for $25 \mathrm{~min}$ at $37^{\circ} \mathrm{C}$ on a rotary shaker in a $\mathrm{CO}_{2}$ incubator. The tissue suspension was then centrifuged for $7 \mathrm{~min}$ at $300 \times \mathrm{g}$, and, the supernatant was discarded. The pellet was resuspended in $2 \mathrm{~mL}$ of Dulbecco's modified medium (DMEM, Invitrogen, Carlsbad, Calif, USA) with $10 \%$ fetal calf serum (FCS) using gentle mechanical trituration; first with a $5 \mathrm{~mL}$ culture pipette and then with two fire-polished silicone-coated pasture pipettes with successively reduced diameters. The volume of media was immediately increased to $20 \mathrm{~mL}$, and undissociated pieces of tissue were allowed to settle for $2 \mathrm{~min}$ before transferring the cell suspension to another culture tube and centrifuging as before. Cells were washed twice, resuspended, and preplated for $1 \mathrm{~h}$ in a culture flask at $37^{\circ} \mathrm{C}$ in a $\mathrm{CO}_{2}$ incubator. Nonadherent cells were gently washed off with DMEM, and the cells were centrifuged and resuspended three times in DMEM. Then cells were counted and concentrated to $3.0 \times 10^{4}$ cells $/ \mu \mathrm{L}$ just prior to transplantation. P75NGFR- and S100-positive cells were counted in short-term cultures made from cell suspensions used for transplantation to assess purity of the cells. Over $95 \%$ of the cells were positive for p75NGFR and S100.

2.2. Immunostaining. To identify OECs, immunostaining for p75NGFR, a characteristic marker for OECs, was performed on cultured OECs. The cells were preincubated in normal goat blocking serum prior to incubation with the primary rabbit anti-p75NGFR monoclonal antibody $(1: 1000$; Chemicon, Temecula, Calif, USA) followed by incubation with a fluorescein isothiocyanate- (FITC-) conjugated IgG ( $1: 2000$, Molecular Probes, Leiden, The Netherlands) secondary antibody for p75NGFR. Photographs were taken on a Spot RT Color CCD.

2.3. Immuno-EM. CNPase transgenic mice were deeply anesthetized (50 mg/kg sodium pentobarbital, i.p.) and perfused transcardially with PBS followed by $4 \%$ paraformaldehyde $/ 0.02 \%$ glutaraldehyde in phosphate-buffered saline (PBS). Olfactory bulbs were excised, postfixed overnight in $4 \%$ paraformaldehyde, and embedded in 3\% agar for vibratome sectioning. Free-floating sections (thickness $150 \mu \mathrm{m})$ were incubated in $2 \%$ normal goat serum for $30 \mathrm{~min}$ and then in rabbit anti-GFP antibody $(1: 2000$; Chemicon) overnight at $4^{\circ} \mathrm{C}$. The sections were incubated overnight with an anti-rabbit biotinylated secondary antibody (Sigma, St. Louis, Mo, USA) and then incubated for $1 \mathrm{~h}$ using a Vectastain Elite ABC kit (Vector Laboratories, Burlingame, Calif, USA). The sections were postfixed with $1 \%$ osmium tetroxide for $4 \mathrm{~h}$, dehydrated in graded ethanol, 


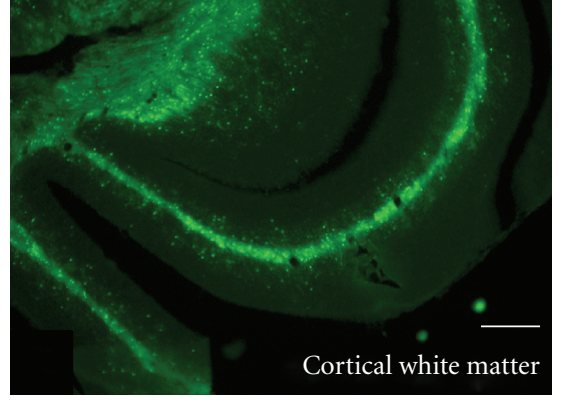

(a)

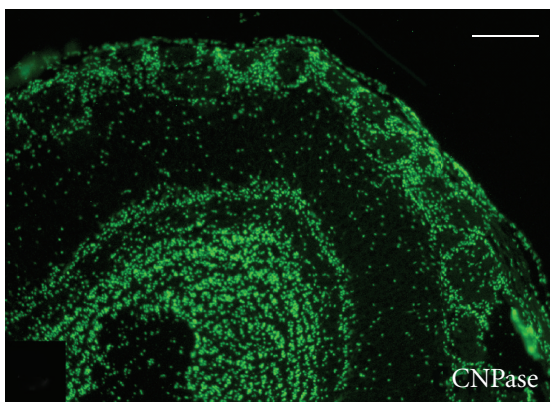

(d)

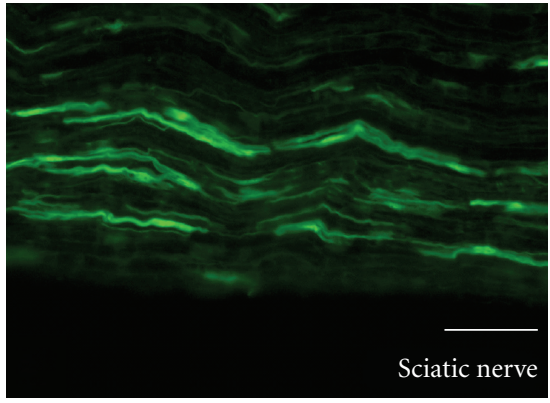

(b)

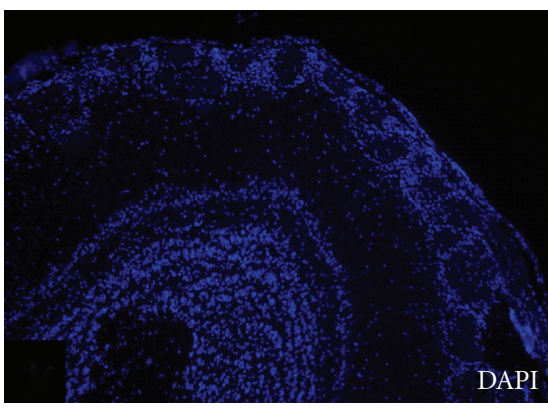

(e)

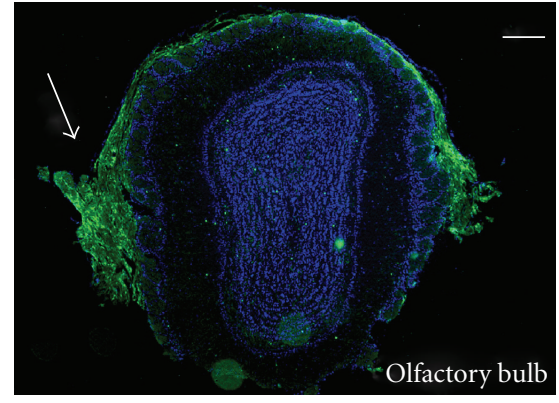

(c)

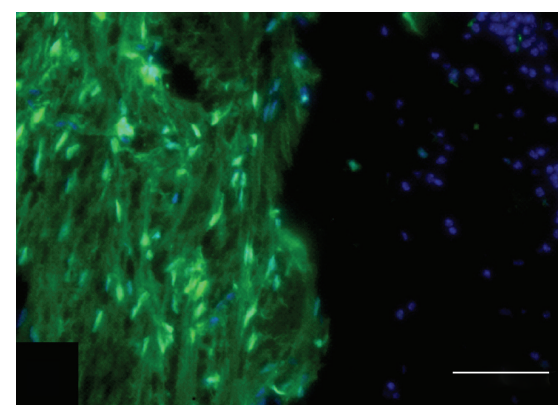

(f)

FIGURE 1: CNPase expression is characteristic of myelinating cells. (a) In the transgenic mouse where GFP is under the control of CNPase, GFP expression can be observed in cortical white matter (a) and sciatic nerve (b). The GFP is present in oligodendrocytes in white matter of the CNS and Schwann cells in the peripheral nerve. (c) Cross-section of the olfactory bulb from the CNPase mouse showing GFP expression in the olfactory nerve (arrow) and the outer nerve layer of the olfactory bulb (OB) where OECs are present as the only glia cell type. (f) Higher power image of the olfactory nerve from (c) showing GFP expression in the nuclei and cytoplasm of OECs in the outer nerve layer. (d) and (e) Immunohistochemistry for CNPase in a wild type mouse OB showing CNPase expression in deep white matter and outer margins of the bulb. Note that the round glomeruli are devoid of CNPase. Nuclei have been counterstained with DAPI (blue) in (c), (e), and (f). Scale bars: (a) $=8 \mu \mathrm{m},(\mathrm{b})=12 \mu \mathrm{m},(\mathrm{c})=500 \mu \mathrm{m},(\mathrm{d})=150 \mu \mathrm{m}$ and pertains to (d) and (e), (f) $=3 \mu \mathrm{m}$.

and embedded in Epox-812 (Ernest Fullam, Latham, NY, USA). Ultrathin sections were cut as described above but were not counterstained.

\subsection{Induction of Nerve Crush Lesion and eGFP-OECs Trans-} plantation Procedure. The Veterans Affairs Connecticut Healthcare System Institutional Animal Care and Use Committee approved all animal protocols. Experiments were performed in accordance with National Institutes of Health guidelines for the care and use of laboratory animals. Adult Sprague Dawley rats (200-225 g) were used for these experiments $(n=12)$. The rats were anesthetized with ketamine $(75 \mathrm{mg} / \mathrm{kg}$ i.p. $)$ and xylazine $(10 \mathrm{mg} / \mathrm{kg}$ i.p.). The sciatic nerve was surgically exposed in anesthetized rats and injured by nerve crush lesion with fine microforceps for 40 seconds. This procedure completely transects all axons within the nerve and the animals showed signs of complete nerve transection [30]. The lesion site was standardized at the level of the piriformis tendon in the thigh. Cultured eGFPexpressing OECs from rat were detached from the culture flasks and resuspended in culture medium and adjusted to a concentration of 30,000 cells $/ \mu \mathrm{L} .2 \mu \mathrm{L}$ of the cell suspension or vehicle alone (sham control) was injected $5.0 \mathrm{~mm}$ by using a Hamilton microsyringe caudally and distally into the crush lesion site. The animals survived for 5 weeks at which time they were intracardially perfused with $4 \%$ paraformaldehyde in phosphate buffer followed by removal of nerves for histological analysis.

\section{Results}

GFP expression in the cortex of the CNPase-eGFP transgenic mouse is strong in oligodendrocytes of cortical white matter (Figure 1(a)). Expression is also observed in Schwann cells of peripheral nerve (Figure 1(b)). Sections through the olfactory bulb in the CNPase-eGFP transgenic mouse indicate intense CNPase expression in the outer nerve layer of the olfactory bulb, the site where OECs are localized and interior regions of the bulb which are rich in oligodendrocytes (Figure 1(c)). Additionally, CNPase was strongly expressed in the olfactory nerve as it enters the olfactory bulb (Figure 1(c); arrow). A higher power image of the olfactory nerve from Figure 1(c) shows GFP expression in the nuclei and cytoplasm of the OECs (Figure 1(e)). Immunohistochemistry for CNPase of the olfactory bulb shows staining in deep white matter as well as in the outer nerve layer (Figure 1(d)).

3.1. Colocalization of p75NGFR with CNPase in OECs in the Olfactory Bulb. The low affinity NGF receptor, p75NGFR, is expressed by OECs and Schwann cells. Cells in the olfactory 


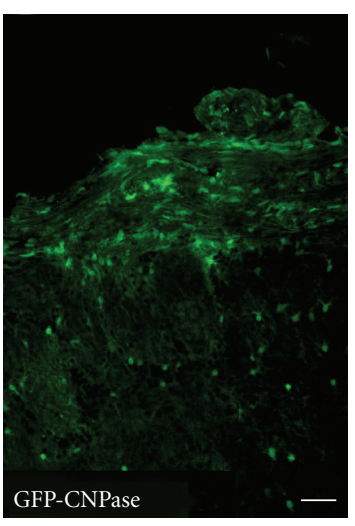

(a)

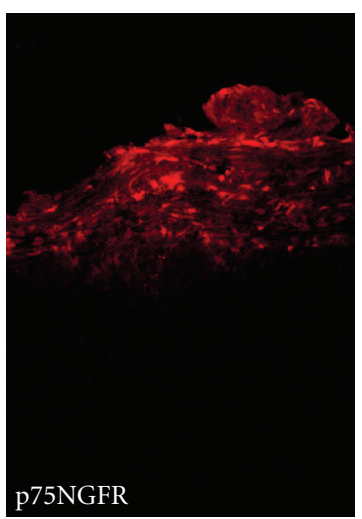

(b)

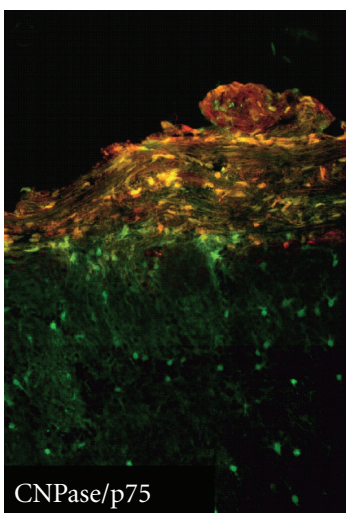

(c)

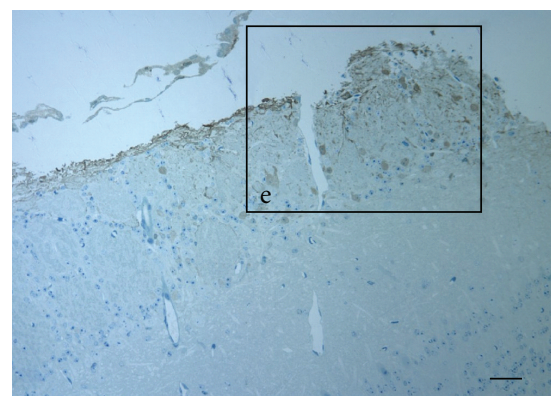

(d)

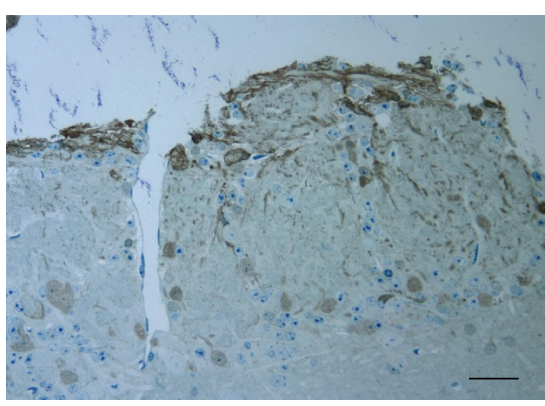

(e)

Figure 2: Colocalization of p75NGFR/CNPase and Immuno-EM. (a) GFP expression in the CNPase mouse in the olfactory nerve as it enters the OB and in scattered cells in the deep OB white matter. Immunostaining for p75 colocalizes with GFP in the olfactory nerve, but not in deep white matter $(\mathrm{a}-\mathrm{c})$. Immunoperoxidase staining for GFP in toluidine blue plastic sections ( $1 \mathrm{um}$ ) shows that the GFP was present in OECs in the outer nerve layer (d, e). Scale bars: in (a), pertains to $(a-c)=10 \mu \mathrm{m},(d)=7,(e)=10 \mu \mathrm{m}$.

nerve layer of eGFP-CNPase transgenic mice showed colocalization of GFP expression with the p75NGFR receptor (Figures 2(a)-2(c)). OECs can readily be identified in olfactory nerve as glial cells ensheathing large numbers of nonmyelinated olfactory nerve fibers and are distributed in the outer nerve layer of the olfactory bulb. For more detailed cellular localization of CNPase, immunoperoxidase staining of the olfactory bulb with a GFP antibody was performed and semithin plastic sections counterstained with toluidine, blue were obtained for more precise localization of eGFP in the OECs of the olfactory bulb and nerves. The eGFP (CNPase expressing cells) was localized in structurally well-defined OECs in the outer nerve layer of the olfactory bulb (Figure 2(d); higher magnification in Figure 2(e)). The cytoplasmic processes of the OECs wrapped bundles of nonmyelinated axons projecting within the outer nerve layer (Figure 2(e)). Thus, coexpression of p75 and CNPase within OECs in the olfactory bulb argues for the remyelination potential of OECs.

\subsection{Cultured OECs from the CNPase Transgenic Mouse Main-} tain Their GFP Expression. The CNPase expression observed in situ was maintained in culture when cells were prepared for cell transplantation (Figures 3(a)-3(d)). Confirmation of OEC identity was established by p75 (Figure 3(b)) immunostaining characteristic of OECs. OECs are the only cells expressing p75NGFR in the olfactory bulb. Dissociated OECs derived from the olfactory bulb and maintained in culture for 4 days had both intense p75NGFR immunostaining and eGFP-CNPase expression (Figure 3(d)).

3.3. OECs Transplanted into Injured Peripheral Nerve Remyelinate Regenerating Axons. OECs prepared from olfactory bulb and transplanted into transected peripheral nerves remyelinate the regenerated axons [2]. The transplanted OECs, shown in green, aligned longitudinally with the regenerated axons (Figure 4(a)). The sciatic nerve crush model (axonotmesis) used completely transects all axons within the nerve. The images for Figure 4 were obtained several millimeters distal to the crush site indicating that regenerated axon were remyelinated by the transplanted OECs. Images of the sciatic nerve at 5 weeks post-OEC transplantation demonstrated an abundance of eGFP-OECs distributing along the injured nerve (Figure 4(a) with inset in (a)). eGFP can be seen in the nuclei and cytoplasm around regenerating peripheral nerve axons. The transplanted eGFP-OECs are longitudinally oriented and associated with neurofilament(NF-) stained axons (inset Figure 4(a)). Longitudinal sections of a group of regenerated axons demonstrated GFPOECs surrounding the axon (Figure 4(b)), and importantly, the remyelinated axons have nodes of Ranvier (Figure 4(b)) with appropriate sodium channel Nav1.6 expression (Figure 4(c)) flanked by the Caspr immunostained paranodes (Figure 4(d); overlay is shown in Figure 4(e)). 


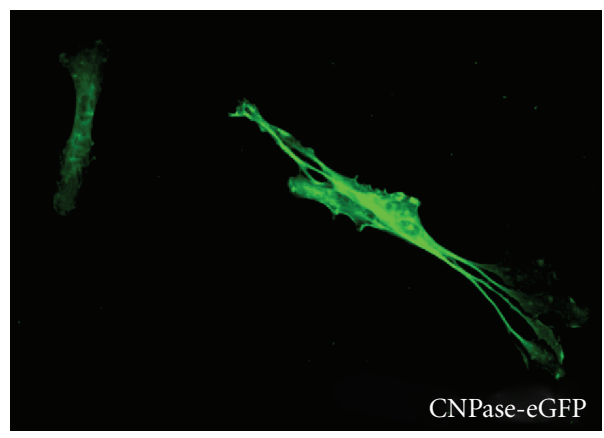

(a)

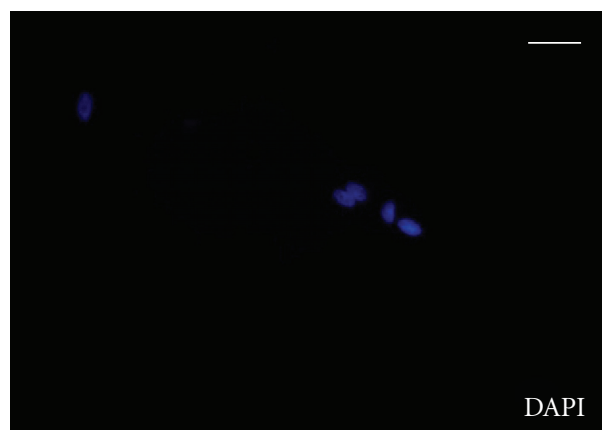

(c)

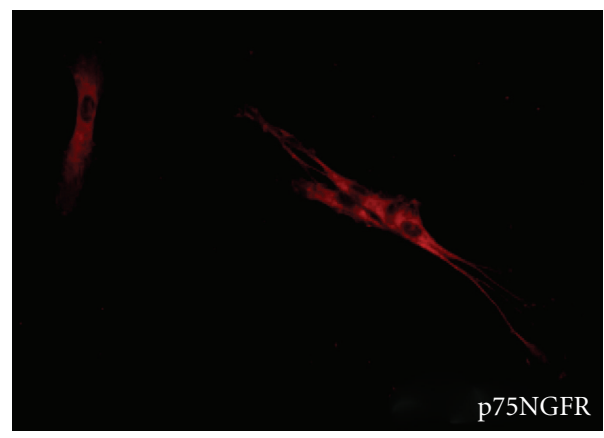

(b)

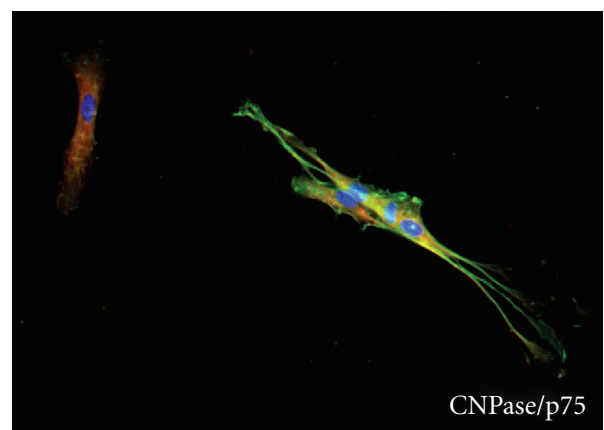

(d)

FIGURE 3: Cultured OECs from the CNPase transgenic mouse maintain their GFP expression. (a-d) Immunostaining of cultured olfactory bulb OECs derived from the eGFP-CNPase mouse indicates colocalization with p75. Nuclei stained blue with DAPI. Note the small cluster of spindle-shaped OECs and a more flattened OEC (upper left) both colocalize GFP (CNPase) and p75. Scale bar: (a) $=5 \mu \mathrm{m}$.

\section{Discussion}

Here we demonstrate that OECs in the outer nerve layer of the olfactory bulb express CNPase, the universal marker for myelinating cells. CNPase expression in OECs is maintained in highly purified cultures and OECs transplanted into injured peripheral nerves remyelinate regenerated nerve fibers. A difficulty in comparing results regarding the remyelinating potential from OEC transplantation studies from various laboratories is that differences are present in the age of the animals used for cell harvesting, purification procedures, and lesion models into which the cells were transplanted. OECs used in the present study were prepared relatively acutely from the outer nerve layer of the adult olfactory bulb; a CNS area rich in OECs in vivo [18]. The degree of cell purity $(>95 \%)$ in our cell suspension as assessed using p75NGFR/S100 immunostaining was about the same as in other studies where immunopanning techniques were used $[14,31]$ or where OECs were prepared from embryonic tissue [32]. Mitotic inhibitors and stimulators of cell proliferation and differentiation were used in those studies. In our cell preparation method from adult tissue, we did not use mitotic inhibitors nor did we stimulate proliferation and differentiation in vivo. Contamination by SCs, which are also p75/S100 positive, in our cultures would be problematic in the interpretation that adult OECs are able to form peripheral-like myelin. However, one would expect at best a very minor contamination of SCs possibly associated with blood vessel innervation [14] or meningeal cells [32].
Such minor contamination could not account for the vast majority $(>95 \%)$ of our cells displaying a p75NGFR/S100 phenotype in relatively acute cell suspensions.

Using transgenic mice which express GFP only in cells which express CNPase, we were able to show that OECs from the outer nerve layer of the olfactory bulb express CNPase and that OEC preparations isolated from this tissue using our isolation methods also express CNPase. This expression is an important prerequisite to demonstrate the myelination potential of OECs.

Transplantation of OECs prepared from adult olfactory bulb into various traumatic spinal cord injury and nerve injury models have demonstrated improved functional recovery. Histologically, axonal regeneration, remyelination, and neuroprotection have been reported following OEC transplantation [33]. However, Li et al. (2007) report that while OECs remyelinated regenerated spinal cord axons that they did not remyelinated regenerated optic nerve axons [34], while Schwann cells did remyelinate some optic nerve axons. Reason for this difference is uncertain. We demonstrated that the migration properties of OECs and SCs are different in the X-irradiated spinal cord: OECs migrate extensively in both gray and white matter and SCs do not [35]. Indeed, a number of unique properties have been described for OECs to distinguish them from SCs [36]. While several groups point out unique properties following in vivo transplantation of OECs as compared to SCs such as the formation of cellular tunnels which provide a permissive environment for axonal regeneration and greater mobility 


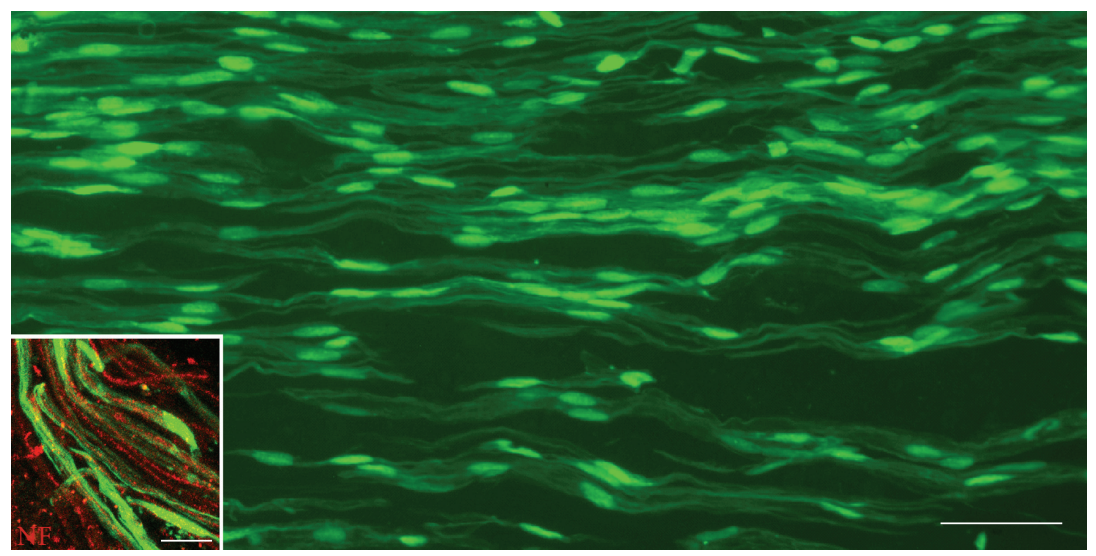

(a)

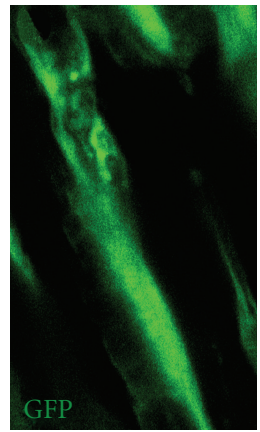

(b)

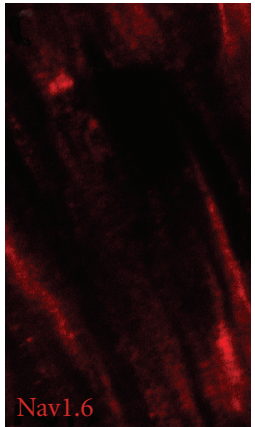

(c)

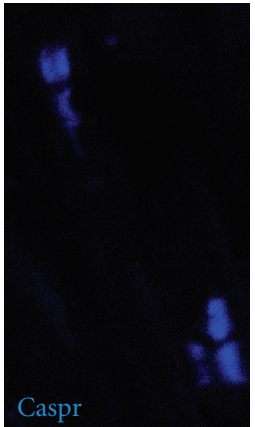

(d)

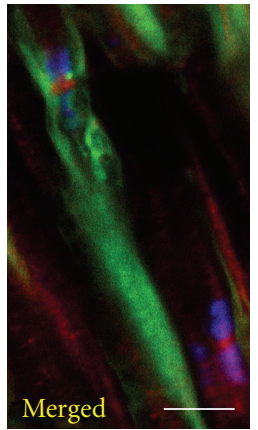

(e)

FIGURE 4: OECs transplanted into injured peripheral nerve remyelinate regenerating axons. (a) GFP can be seen in the nuclei and cytoplasm around regenerating peripheral nerve axons. The inset indicates that the GFP elements are longitudinally oriented with neurofilament(NF-) stained regenerated axons. (b-e) Longitudinal section of a group of regenerated axons with GFP cells (b) surrounding the axons and sodium channel Nav1.6 (c) being flanked by the Caspr immunostained paranodes (d) indicating that the transplanted OECs can remyelinate regenerated axons which form appropriate sodium channels at the newly formed nodes of Ranvier (overlay in (e)). Scale bars: $(\mathrm{a})=50 \mu \mathrm{m}$ (a), (b-e), and (a) inset in (a) $=5 \mu \mathrm{m}$.

in astrocytic regions [36] others suggest that the functional benefits of OEC transplantation may result from recruitment of endogenous SCs by the OECs $[13,19]$.

Currently, a number of clinical studies are underway exploring the potential clinical utility of OEC transplantation in spinal cord injury patients [37-41]. Better understanding of the ability of transplanted OECs to improve functional outcome and direct comparison to transplanted SCs in CNS injury will have an impact on the direction of future research directed toward clinical applications.

\section{Conclusion}

The results of this study indicate that OECs in the outer nerve layer of the olfactory bulb express CNPase, a universal marker for myelinating cells. CNPase expression in OECs is maintained in highly purified cultures and colocalizes in cells with p75 receptor expression. Moreover, in culture the OECs maintain strong eGFP-CNPase expression. OECs transplanted into injured peripheral nerves remyelinate regenerated nerve fibers which formed nodes of Ranvier with high density of sodium channels between the myelin segments formed by the transplanted OECs. These data demonstrate that OECs share the molecular machinery of CNPase expression with oligodendrocytes and Schwann cells indicating a third dominant myelinating cell type within the nervous system. These results encourage ongoing work with OECs as a therapeutic tool in peripheral nerve repair, in CNS trauma and demyelinating diseases.
Abbreviations
CNPase: $2^{\prime}-3^{\prime}$-cyclic nucleotide $3^{\prime}$-phosphodiesterase
CNS: Central nervous system
DMEM: Dulbecco's modified medium
eGFP: Enhanced green fluorescent protein
FCS: Fetal calf serum
FITC: Fluorescein isothiocyanate
Nav1.6: Sodium channel subtype 1.6
NF: Neurofilament
OECs: Olfactory ensheathing cells
ONL: Outer nerve layer 
OPC: $\quad$ Oligodendrocyte precursor cells

PBS: $\quad$ Phosphate-buffered saline

p75NGFR: P75 nerve growth factor receptor

PNS: $\quad$ Peripheral nervous system.

\section{Acknowledgments}

This work was supported in part by the Medical and Research and Development Services of the Department of Veterans Affairs, the NIH, the National Multiple Sclerosis, Society and the German Research Foundation (FOR 1103: Ra 1901/1-1). The authors thank Heather Mallozzi and Margaret Borelli for excellent technical assistance.

\section{References}

[1] M. A. Dombrowski, M. Sasaki, K. L. Lankford, J. D. Kocsis, and C. Radtke, "Myelination and nodal formation of regenerated peripheral nerve fibers following transplantation of acutely prepared olfactory ensheathing cells," Brain Research, vol. 1125, no. 1, pp. 1-8, 2006.

[2] C. Radtke, A. A. Aizer, S. K. Agulian, K. L. Lankford, P. M. Vogt, and J. D. Kocsis, "Transplantation of olfactory ensheathing cells enhances peripheral nerve regeneration after microsurgical nerve repair," Brain Research, vol. 1254, no. 13, pp. 10-17, 2009.

[3] T. Imaizumi, K. L. Lankford, and J. D. Kocsis, “Transplantation of olfactory ensheathing cells or Schwann cells restores rapid and secure conduction across the transected spinal cord," Brain Research, vol. 854, no. 1-2, pp. 70-78, 2000.

[4] Y. Li, P. M. Field, and G. Raisman, "Repair of adult rat corticospinal tract by transplants of olfactory ensheathing cells," Science, vol. 277, no. 5334, pp. 2000-2002, 1997.

[5] Y. Li, P. M. Field, and G. Raisman, "Regeneration of adult rat corticospinal axons induced by transplanted olfactory ensheathing cells," Journal of Neuroscience, vol. 18, no. 24, pp. 10514-10524, 1998.

[6] T. Imaizumi, K. L. Lankford, W. V. Burton, W. L. Fodor, and J. D. Kocsis, "Xenotransplantation of transgenic pig olfactory ensheathing cells promotes axonal regeneration in rat spinal cord," Nature Biotechnology, vol. 18, no. 9, pp. 949-953, 2000.

[7] A. Ramón-Cueto, G. W. Plant, J. Avila, and M. B. Bunge, "Long-distance axonal regeneration in the transected adult rat spinal cord is promoted by olfactory ensheathing glia transplants," Journal of Neuroscience, vol. 18, no. 10, pp. 38033815, 1998.

[8] A. Ramón-Cueto, M. I. Cordero, F. F. Santos-Benito, and J. Avila, "Functional recovery of paraplegic rats and motor axon regeneration in their spinal cords by olfactory ensheathing glia," Neuron, vol. 25, no. 2, pp. 425-435, 2000.

[9] N. Keyvan-Fouladi, G. Raisman, and Y. Li, "Functional repair of the corticospinal tract by delayed transplantation of olfactory ensheathing cells in adult rats," Journal of Neuroscience, vol. 23, no. 28, pp. 9428-9434, 2003.

[10] J. Lu, F. Féron, A. Mackay-Sim, and P. M. E. Waite, "Olfactory ensheathing cells promote locomotor recovery after delayed transplantation into transected spinal cord," Brain, vol. 125, no. 1, pp. 14-21, 2002.

[11] R. J. M. Franklin, J. M. Gilson, I. A. Franceschini, and S. C. Barnett, "Schwann cell-like myelination following transplantation of an olfactory bulb-ensheathing cell line into areas of demyelination in the adult CNS," Glia, vol. 17, no. 3, pp. 217224, 1996.

[12] G. W. Plant, C. L. Christensen, M. Oudega, and M. B. Bunge, "Delayed transplantation of olfactory ensheathing glia promotes sparing/regeneration of supraspinal axons in the contused adult rat spinal cord," Journal of Neurotrauma, vol. 20, no. 1, pp. 1-16, 2003.

[13] J. G. Boyd, J. Lee, V. Skihar, R. Doucette, and M. D. Kawaja, "LacZ-expressing olfactory ensheathing cells do not associate with myelinated axons after implantation into the compressed spinal cord," Proceedings of the National Academy of Sciences of the United States of America, vol. 101, no. 7, pp. 2162-2166, 2004.

[14] T. Takami, M. Oudega, M. L. Bates, P. M. Wood, N. Kleitman, and M. B. Bunge, "Schwann cell but not olfactory ensheathing glia transplants improve hindlimb locomotor performance in the moderately contused adult rat thoracic spinal cord," Journal of Neuroscience, vol. 22, no. 15, pp. 6670-6681, 2002.

[15] T. Imaizumi, K. L. Lankford, S. G. Waxman, C. A. Greer, and J. D. Kocsis, "Transplanted olfactory ensheathing cells remyelinate and enhance axonal conduction in the demyelinated dorsal columns of the rat spinal cord," Journal of Neuroscience, vol. 18, no. 16, pp. 6176-6185, 1998.

[16] M. Sasaki, J. A. Black, K. L. Lankford, H. A. Tokuno, S. G. Waxman, and J. D. Kocsis, "Molecular reconstruction of nodes of Ranvier after remyelination by transplanted olfactory ensheathing cells in the demyelinated spinal cord," Journal of Neuroscience, vol. 26, no. 6, pp. 1803-1812, 2006.

[17] Y. Akiyama, K. L. Lankford, C. Radtke, C. A. Greer, and J. D. Kocsis, "Remyelination of spinal cord axons by olfactory ensheathing cells and Schwann cells derived from a transgenic rat expressing alkaline phosphatase marker gene," Neuron Glia Biology, vol. 1, no. 1, pp. 47-55, 2004.

[18] T. Kato, O. Honmou, T. Uede, K. Hashi, and J. D. Kocsis, "Transplantation of human olfactory ensheathing cells elicits remyelination of demyelinated rat spinal cord," Glia, vol. 30, no. 3, pp. 209-218, 2000.

[19] J. G. Boyd, R. Doucette, and M. D. Kawaja, "Defining the role of olfactory ensheathing cells in facilitating axon remyelination following damage to the spinal cord," FASEB Journal, vol. 19, no. 7, pp. 694-703, 2005.

[20] J. G. Boyd, A. Jahed, T. G. McDonald et al., "Proteomic evaluation reveals that olfactory ensheathing cells but not schwann cells express calponin," Glia, vol. 53, no. 4, pp. 434440, 2006.

[21] X. Yuan, R. Chittajallu, S. Belachew, S. Anderson, C. J. McBain, and V. Gallo, "Expression of the green fluorescent protein in the oligodendrocyte lineage: a transgenic mouse for developmental and physiological studies," Journal of Neuroscience Research, vol. 70, no. 4, pp. 529-545, 2002.

[22] M. Gravel, J. Peterson, V. W. Yong, V. Kottis, B. Trapp, and P. E. Braun, 'Overexpression of 2',3'-cyclic nucleotide 3'phosphodiesterase in transgenic mice alters oligodendrocyte development and produces aberrant myelination," Molecular and Cellular Neurosciences, vol. 7, no. 6, pp. 453-466, 1996.

[23] X. Yin, J. Peterson, M. Gravel, P. E. Braun, and B. D. Trapp, "CNP overexpression induces aberrant oligodendrocyte membranes and inhibits MBP accumulation and myelin compaction," Journal of Neuroscience Research, vol. 50, no. 2, pp. 238-247, 1997.

[24] A. Santos-Silva and L. A. Cavalcante, "Expression of the non-compact myelin protein 2',3'-cyclic nucleotide 3'-phosphodiesterase (CNPase) in olfactory bulb ensheathing glia 
from explant cultures," Neuroscience Research, vol. 40, no. 2, pp. 189-193, 2001.

[25] S. K. Pixley, "Characterization of olfactory receptor neurons and other cell types in dissociated rat olfactory cell cultures," International Journal of Developmental Neuroscience, vol. 14, no. 7-8, pp. 823-839, 1996.

[26] S. S. Gomes, S. L. Carvalho, M. F. Santiago, L. B. Lopez, P. C. Barradas, and L. A. Cavalcante, "Expression of 2',3'-cyclic nucleotide 3'-phosphodiesterase (CNPase) in the developing olfactory bulb and subventricular zone rostral extension," Journal of Neuroscience Research, vol. 73, no. 4, pp. 471-480, 2003.

[27] X. Yuan, R. Chittajallu, S. Belachew, S. Anderson, C. J. McBain, and V. Gallo, "Expression of the green fluorescent protein in the oligodendrocyte lineage: a transgenic mouse for developmental and physiological studies," Journal of Neuroscience Research, vol. 70, no. 4, pp. 529-545, 2002.

[28] M. Sasaki, K. L. Lankford, M. Zemedkun, and J. D. Kocsis, "Identified olfactory ensheathing cells transplanted into the transected dorsal funiculus bridge the lesion and form myelin," Journal of Neuroscience, vol. 24, no. 39, pp. 84858493, 2004.

[29] M. Sasaki, B. C. Hains, K. L. Lankford, S. G. Waxman, and J. D. Kocsis, "Protection of corticospinal tract neurons after dorsal spinal cord transection and engraftment of olfactory ensheathing cells," Glia, vol. 53, no. 4, pp. 352-359, 2006.

[30] C. Hildebrand, J. D. Kocsis, S. Berglund, and S. G. Waxman, "Myelin sheath remodelling in regenerated rat sciatic nerve," Brain Research, vol. 358, no. 1-2, pp. 163-170, 1985.

[31] R. Devon and R. Doucette, "Olfactory ensheathing cells myelinate dorsal root ganglion neurites," Brain Research, vol. 589, no. 1, pp. 175-179, 1992.

[32] A. Lakatos, P. M. Smith, S. C. Barnett, and R. J. M. Franklin, "Meningeal cells enhance limited CNS remyelination by transplanted olfactory ensheathing cells," Brain, vol. 126, no. 3, pp. 598-609, 2003.

[33] C. Radtke, M. Sasaki, K. L. Lankford, P. M. Vogt, and J. D. Kocsis, "Potential of olfactory ensheathing cells for cellbased therapy in spinal cord injury," Journal of Rehabilitation Research and Development, vol. 45, no. 1, pp. 141-152, 2008.

[34] Y. Li, D. Li, and G. Raisman, "Transplanted Schwann cells, not olfactory ensheathing cells, myelinate optic nerve fibres," Glia, vol. 55, no. 3, pp. 312-316, 2007.

[35] K. L. Lankford, M. Sasaki, C. Radtke, and J. D. Kocsis, "Olfactory ensheathing cells exhibit unique migratory, phagocytic, and myelinating properties in the X-irradiated spinal cord not shared by Schwann cells," Glia, vol. 56, no. 15, pp. 1664-1678, 2008.

[36] J. D. Kocsis, K. L. Lankford, M. Sasaki, and C. Radtke, "Unique in vivo properties of olfactory ensheathing cells that may contribute to neural repair and protection following spinal cord injury," Neuroscience Letters, vol. 456, no. 3, pp. 137-142, 2009.

[37] H. Huang, L. Chen, H. Wang et al., "Safety of fetal olfactory ensheathing cell transplantation in patients with chronic spinal cord injury. A 38-month follow-up with MRI," Zhongguo Xiu Fu Chong Jian Wai Ke Za Zhi, vol. 20, no. 4, pp. 439443, 2006.

[38] F. Féron, C. Perry, J. Cochrane et al., "Autologous olfactory ensheathing cell transplantation in human spinal cord injury," Brain, vol. 128, no. 12, pp. 2951-2960, 2005.
[39] B. H. Dobkin, A. Curt, and J. Guest, "Cellular transplants in China: observational study from the largest human experiment in chronic spinal cord injury," Neurorehabilitation and Neural Repair, vol. 20, no. 1, pp. 5-13, 2006.

[40] C. Lima, J. Pratas-Vital, P. Escada, A. Hasse-Ferreira, C. Capucho, and J. D. Peduzzi, "Olfactory mucosa autografts in human spinal cord injury: a pilot clinical study," Journal of Spinal Cord Medicine, vol. 29, no. 3, pp. 191-204, 2006.

[41] K. Senior, "Olfactory ensheathing cells to be used in spinalcord repair trial," Lancet Neurol, vol. 1, no. 5, p. 269, 2002. 

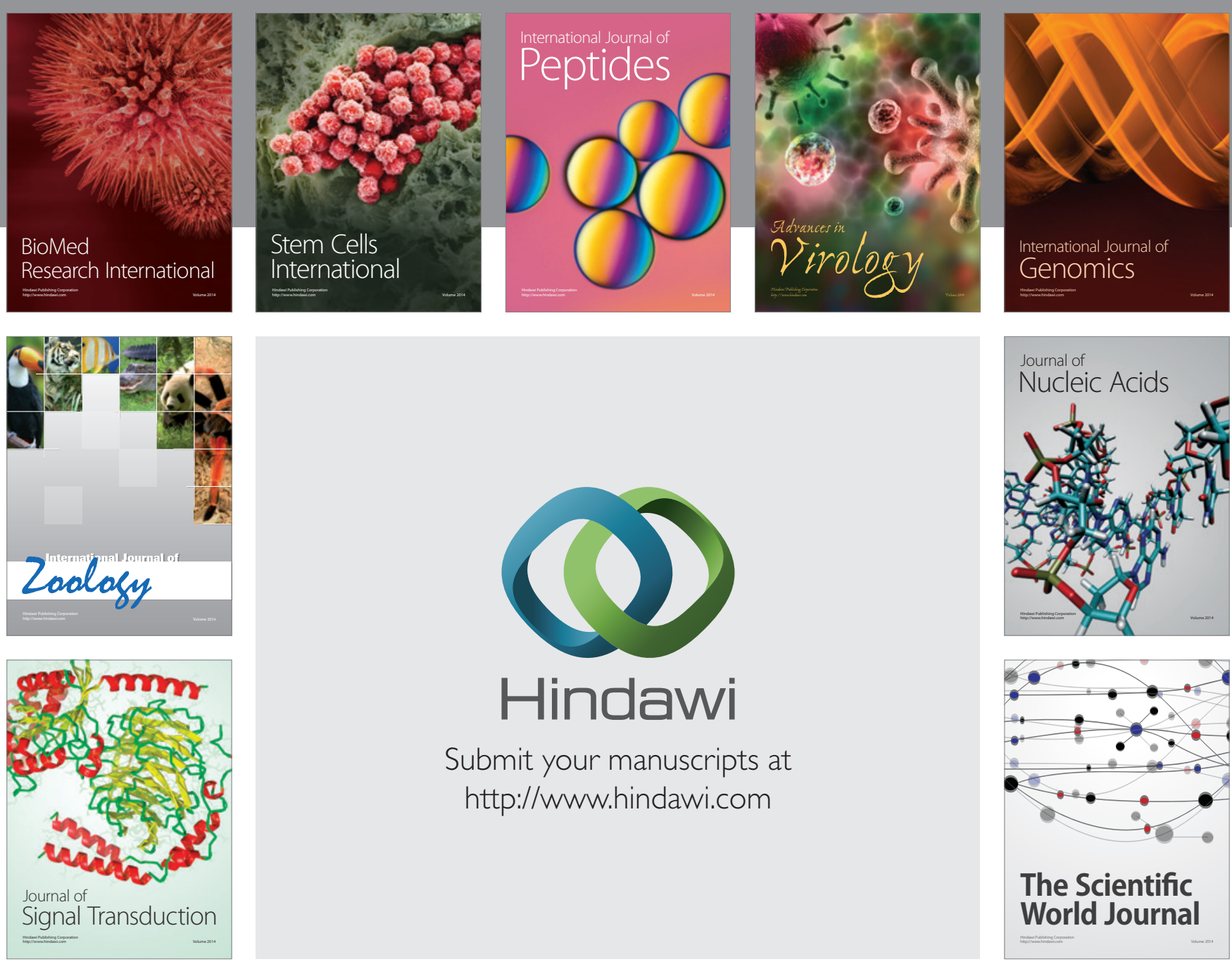

Submit your manuscripts at

http://www.hindawi.com
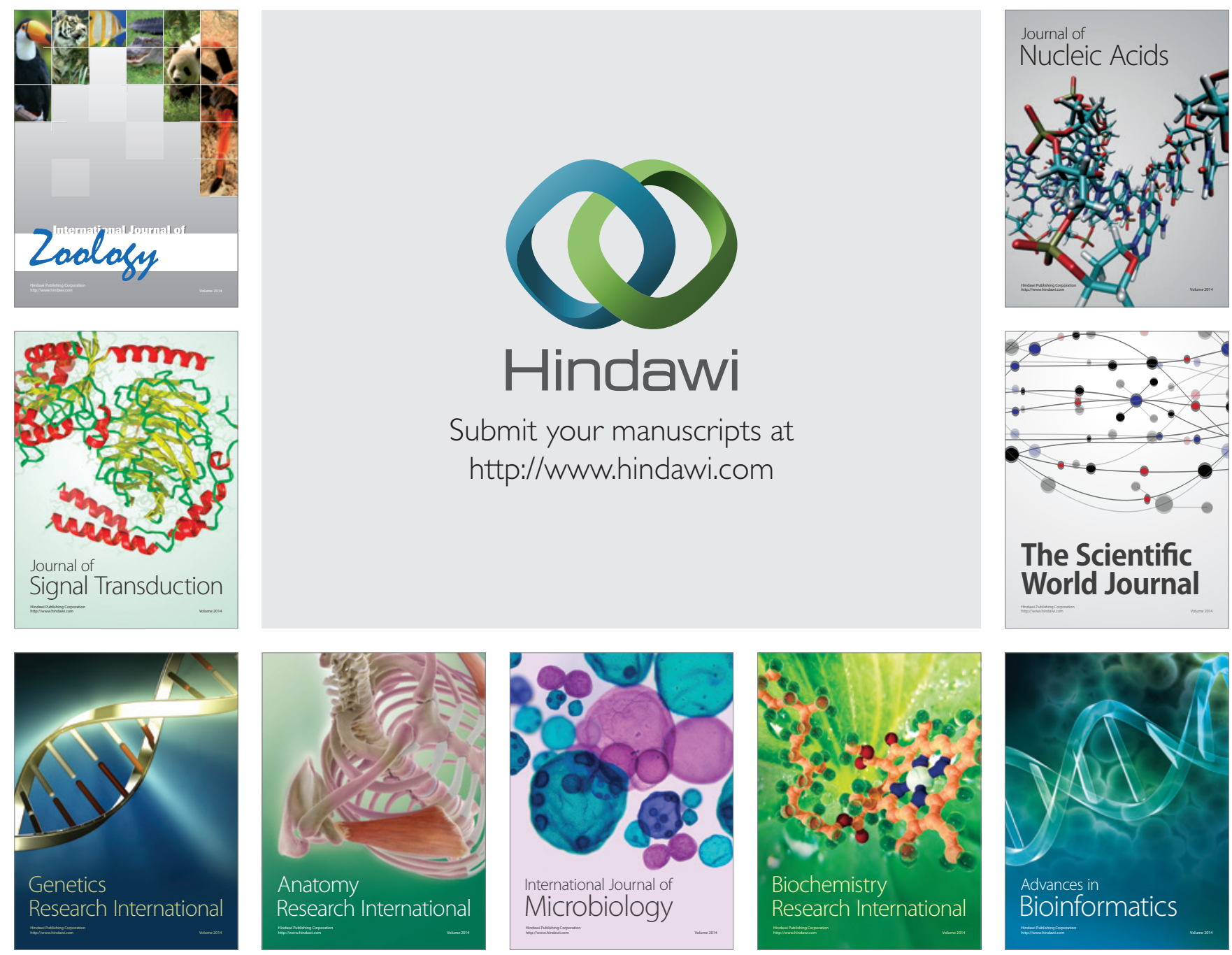

The Scientific World Journal
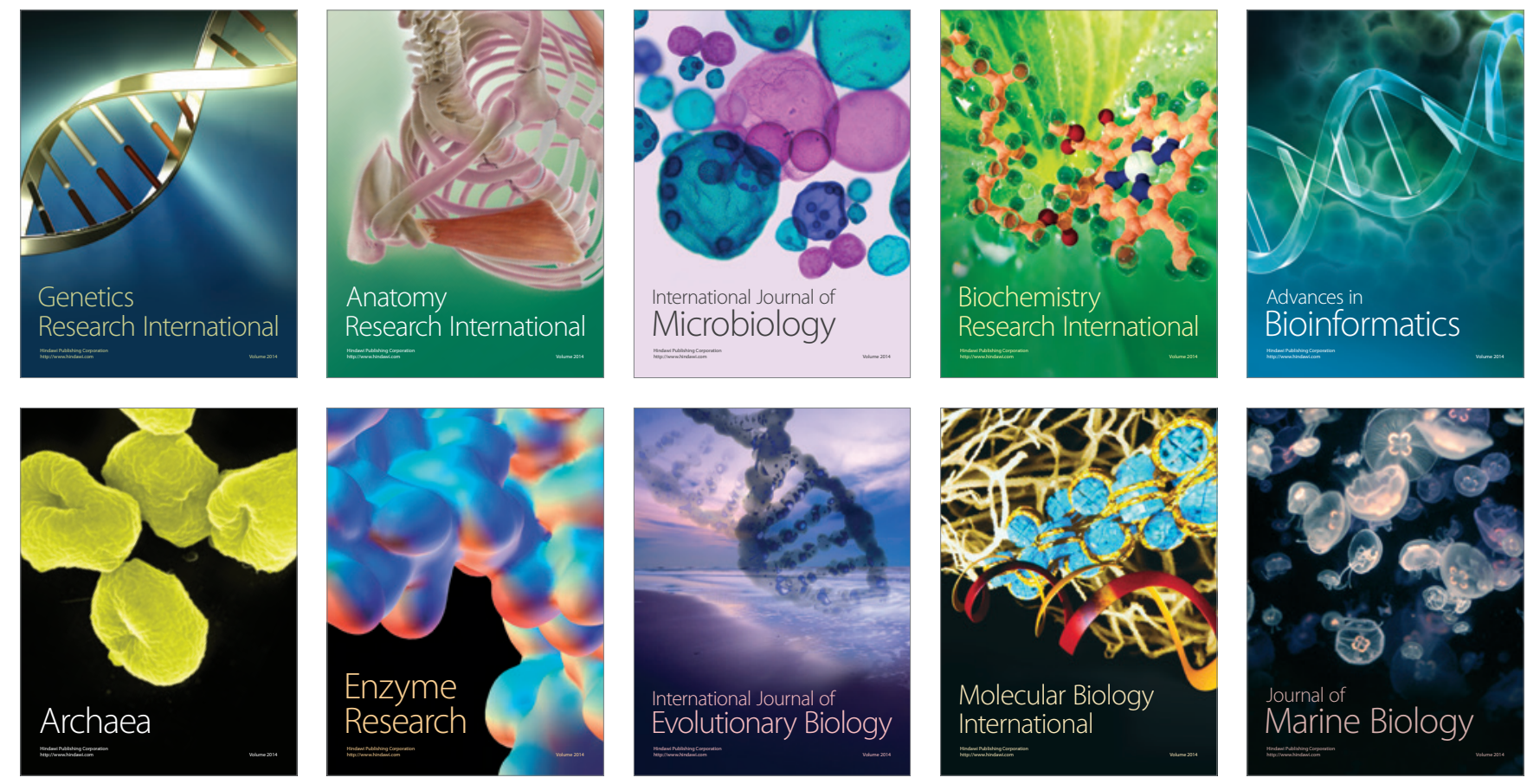